\title{
O delineamento de tarefas matemáticas à luz da pesquisa de desenvolvimento: uma oportunidade de reflexão para a prática pedagógica
}

Cleiton Antonio Marino cleitonmarino@gmail.com $\frac{\text { orcid.org/0000-0002-3789-666X }}{\text { Universidade Tecnológica Federal do }}$ Paraná (UTFPR), Londrina, Paraná, Brasil

\section{Marcele Tavares Mendes} marceletavares@utfpr.edu.br orcid.org /0000-0001-6844-6525 Universidade Tecnológica Federal do Paraná (UTFPR), Londrina, Paraná, Brasil

\section{RESUMO}

O presente trabalho é recorte de uma pesquisa de mestrado em andamento, que visa analisar o processo de elaboração de uma trajetória de ensino e de aprendizagem envolvida no contexto de plantas baixas - para alunos do 6ㅇ ano do Ensino Fundamental. Toda reflexão fundamenta-se nos princípios da abordagem de ensino Educação Matemática Realística que: reconhece a matemática como uma atividade humana, propõe um contexto de sala de aula em que o aluno se reconhece protagonista e responsável por seu processo de aprendizagem e, o professor como um guia que orienta e acompanha seus alunos, por meio de intervenções, na direção dos objetivos da educação desejada. De modo específico, neste trabalho, o objetivo é apresentar uma reflexão construída a partir de um ciclo iterativo de aplicação e refinamento de uma das tarefas que compõem o primeiro design da trajetória de ensino e de aprendizagem, na direção de apresentar e discutir aspectos de sua aplicação, análise, avaliação e reformulação para novo design e novo ciclo iterativo. Trata-se de um estudo de natureza qualitativa de cunho interpretativo em que o processo de sua elaboração baseia-se na Pesquisa de Desenvolvimento (Design Research). A fase de aplicação do primeiro ciclo iterativo ocorreu com um grupo de oito alunos do 60 ano do Ensino Fundamental em uma escola estadual do Paraná, no segundo semestre de 2017. Pudemos inferir que para um professor vivenciar e analisar o processo de evolução e delineamento de enunciados de tarefas matemáticas possibilita uma reflexão e aprimoramento de sua prática pedagógica, assim como explorar contextos em tarefas de matemática em aulas desenvolvidas à luz dos princípios da Educação Matemática Realística faz-se uma alternativa para superar uma abordagem de ensino de matemática convencional.

PALAVRAS-CHAVE: Educação Matemática Realística. Trajetória de ensino e aprendizagem. Tarefas matemáticas. Pesquisa de Desenvolvimento. 


\section{INTRODUÇÃO}

$\mathrm{Na}$ busca por caminhos que possam contribuir para o processo de ensino e aprendizagem, educadores matemáticos e pesquisadores vêm desenvolvendo estudos e estratégias focadas na interação do aluno com situações cotidianas. Uma característica dessas estratégias é o aluno ser protagonista de seu processo de aprendizado, que ainda precisa ser apropriadamente inserido nos contextos da sala de aula. É preciso, assim, que se abra mão das orientações mais tradicionais de ensino para que outras ganhem espaço e possibilitem esse protagonismo (SARAIVA; PONTE, 2003; MARIN, 2012; WEININGER, 2001; FARIA, 2004).

Nesta perspectiva, o uso de propostas didáticas por meio de tarefas que estimulem os alunos a desencadearem processos de organização e reconhecimento da necessidade de instrumentos matemáticos e de sua manipulação correta. Nessa direção, as tarefas que os alunos desenvolvem em sala de aula ou em casa, aliadas a uma abordagem de ensino coerente, precisam ser selecionadas ou elaboradas de um modo que possuam potencial para que os alunos explorem possibilidades, desenvolvam estratégias de resolução, analisem a relação do contexto da tarefa com a matemática e até mesmo redescubram a própria Matemática (FREUDENTHAL, 1973; VAN DEN HEUVEL-PANHUIZEN, 2010; SMITH; STEIN, 1998).

No presente trabalho, apresentamos resultados parciais de uma pesquisa de mestrado em andamento que, com base na abordagem de ensino Educação Matemática Realística $\left(\mathrm{RME}^{1}\right)$, visa elaborar um produto educacional ${ }^{2}$ composto por tarefas matemáticas - que em comum referem-se às plantas baixas de casas e da própria sala de aula - que serão compiladas em uma trajetória de ensino e de aprendizagem ${ }^{3}$ para alunos do 60 ano do Ensino Fundamental que vai ao encontro de um currículo que integra conteúdos de domínios matemáticos distintos. Neste artigo, especificamente, temos como objetivo investigar que aspectos influenciam um professor ao delinear, aplicar e revisar uma tarefa que compõe uma trajetória de ensino e de aprendizagem para o 6o ano do Ensino Fundamental à luz da Educação Matemática Realística?

Com isso, subsidiamos nossas reflexões na análise de um ciclo de iteração de aplicação de uma tarefa (tarefa 5) do primeiro desenho da trajetória de ensino e de aprendizagem. Ela foi aplicada a um grupo de 8 alunos do 6o ano do Ensino Fundamental de uma escola estadual do Paraná na cidade de Londrina no segundo semestre de 2017. O processo metodológico desse ciclo de iteração baseia-se na abordagem de Pesquisa em Desenvolvimento (Design Research).

Para tanto, apresentamos uma discussão dos resultados e as inferências realizadas acerca da questão da investigação, tomando como ponto de partida a apresentação e a discussão do processo de construção desse produto educacional à luz da Pesquisa de Desenvolvimento por meio da proposição da abordagem de ensino escolhida e seus princípios. Em seções próprias expomos aspectos dos procedimentos metodológicos da Pesquisa em Desenvolvimento e os reconhecemos no estudo. Em seguida apresentamos e discutimos o delineamento de uma tarefa da trajetória de ensino e de aprendizagem para seu estado atual. Finalizamos com as nossas considerações finais, seguidas das referências bibliográficas. 


\section{A ABORDAGEM DE ENSINO EDUCAÇÃO MATEMÁTICA REALÍSTICA}

A Educação Matemática Realística (RME) foi selecionada como a abordagem de ensino para o desenvolvimento da pesquisa por ter os papéis do professor e do aluno em um ambiente de sala de aula distintos dos convencionais ${ }^{4}$. Os alunos constroem uma matemática a partir do lidar com tarefas em um contexto realizável ou imaginável. Por intermédio dessas tarefas, ocorre o processo de matematização, que é a organização de uma realidade por meio da matemática (DE LANGE, 1987). O professor, por sua vez, planeja e coordena todo esse processo, providencia e disponibiliza os materiais necessários, auxilia e instiga o aluno com orientações e questionamentos. O professor guia e acompanha o processo de aprendizagem de cada aluno.

Segundo Gravemeijer (2005):

[...] o professor continua a ser a autoridade na sala de aula, mas de uma forma diferente, ele passa a definir as regras do que é a Matemática e o que significa aprender Matemática na sua sala de aula. Além disso, o professor escolhe as atividades de ensino, escolhe tópicos para discussão, e orquestra as discussões em grupo turma, de tal forma que estas contribuam para a Matemática que se pretende ensinar. Ao fazê-lo, têm de descobrir um equilíbrio entre o "guiar" e o "re(inventar)". Resumidamente, é o professor que molda a inovação curricular que está aqui implícita (GRAVEMEIJER, 2005, p. 22).

Um dos pressupostos dessa abordagem de ensino é a matemática como atividade humana. Esse pressuposto tem reflexo direto no ensino da matemática, uma vez que revela a essência da matemática que o aluno deve vivenciar em sala de aula. Conforme descrevem Ferreira e Buriasco (2016):

[...] a essência da Educação Matemática não reside no ensino dos objetos matemáticos simplesmente, mas sim na atividade: um processo de organização e tratamento de um assunto por meio desses objetos. Sendo a matemática vista como uma ação, não faz sentido ensiná-la como uma sucessão de conteúdos "prontos para o consumo" sem dar aos alunos diferentes oportunidades para experienciar a matemática como uma "atividade humana" Nesse sentido, os conteúdos, conceitos, objetos, ideias, algoritmos, propriedades matemáticas emergem dos fenômenos com os quais os alunos podem se envolver ao lidar com um assunto, em vez de ser o ponto de partida (FERREIRA, BURIASCO, 2016, p. 243).

As situações pelas quais podem emergir a matemática sistematizada na perspectiva da Educação Matemática Realística são os contextos concretos ou imagináveis pelos alunos, que doravante será denominado neste texto por contexto realístico, que podem contribuir para que ocorra o processo de matematização.

A reinvenção guiada é a estratégia de ensino inerente à RME (GRAVEMEIJER, 2005). O processo de matematização dos alunos envolvidos em uma reinvenção guiada ocorre a partir do lidar com uma tarefa. Nessa estratégia, é determinante o conjunto de orientações e questionamentos do professor durante o processo de ensino e aprendizagem. Desse modo, o professor guia o processo de matematização, orientando-os a utilizar seus próprios conhecimentos para, posteriormente, chegarem aos procedimentos formais, podendo tornar possível 
que o aluno sistematize conhecimentos matemáticos construídos historicamente (FREUDENTHAL, 1991).

O professor guia com o intuito de acompanhar o aluno em suas produções, a fim de elaborar intervenções para que o próprio aluno construa seu conhecimento a partir do lidar com a matemática como uma ferramenta (MENDES, 2014).

Em sua dissertação, Silva (2015) fez uma revisão bibliográfica de diversos estudos publicados a respeito da Educação Matemática Realística, para apresentar uma configuração da reinvenção guiada. Um dos aspectos destacado por ele é o fato de domínios do conhecimento matemático serem considerados entrelaçados. Esse aspecto se refere a um dos princípios da RME: o princípio do entrelaçamento.

O princípio do entrelaçamento significa que os domínios do conhecimento matemático como número, geometria, medidas, e tratamento da informação não são considerados como capítulos isolados no currículo, mas como fortemente integrados (VAN DEN HEUVEL-PANHUIZEN, 2010b, p. 5).

Além do entrelaçamento, Van Den Heuvel-Paunhuizen (2010) apresenta outros cinco princípios da Educação Matemática Realística: da atividade, que se refere à matemática como atividade humana; da realidade, pois o processo de matematização ocorre a partir de um contexto realístico; de níveis, em que os alunos perpassam por distintos níveis de compreensão, partindo dos processos informais até que, de modo progressivo, atinjam os modelos mais formais; da interatividade, pois se a matemática é uma atividade humana, ela também se dá por meio da socialização; de orientação, pois o uso da estratégia de ensino reinvenção guiada direciona o aluno à oportunidade de descobrir a matemática.

Valendo-nos de reflexões acerca desses princípios da RME, consideramos pertinente elaborar uma trajetória de ensino e aprendizagem para que, ao explorarem um contexto realístico, os alunos tenham a oportunidade de sistematizar conhecimentos geométricos, numéricos, de medidas e de tratamento da informação apoiados no material didático.

Entre as inúmeras possibilidades de contextos a serem explorados em tarefas para promover a aprendizagem matemática, escolhemos os elementos que compõem a casa do aluno e a própria sala de aula, representados em uma planta baixa. Elaborar, reproduzir e rascunhar plantas baixas é uma prática que pode desenvolver importantes habilidades no contexto escolar, como o desenvolvimento da percepção espacial, a capacidade de conversão de medidas para o uso adequado de escalas dos projetos e o estudo de adição e multiplicação de números decimais para o cálculo do perímetro e da área de cada cômodo representado.

A produção de materiais, pelo professor, como uma trajetória de ensino e aprendizagem, que contém tarefas e reflexões das mesmas, elaborada a partir de um contexto realístico, pode ser suporte adequado para que os alunos desenvolvam o processo de matematização com a utilização da reinvenção guiada. É nesse momento de planejamento que o professor prevê como irá conduzir as tarefas, de modo que favoreça a aprendizagem. 


\section{A ABORDAGEM METODOLÓGICA E OS PASSOS PERCORRIDOS}

O processo de elaboração das tarefas que integrarão a trajetória de ensino e aprendizagem vem ocorrendo a partir de uma pesquisa qualitativa de cunho interpretativo, à luz da Pesquisa de Desenvolvimento, conhecida internacionalmente como Design Research, Design-based Research ou Development Research.

De maneira geral, podemos dizer que uma "pesquisa de desenvolvimento" refere-se àquelas investigações que envolvem delineamento, como a elaboração do artefato em sua primeira versão, sendo que o desenvolvimento refere-se ao processo contínuo de seu refinamento por meio da avaliação sistemática (BARBOSA; OLIVEIRA, 2015, p. 527).

No contexto da educação, essa abordagem de pesquisa pode ser desenvolvida com intenção de elaborar produtos educacionais. O estudo se inicia com a definição do problema, com uma consulta entre os sujeitos envolvidos; passa pela formulação da questão de pesquisa; e ocorre o estudo do contexto e a literatura.

Em um segundo momento, ocorre o desenvolvimento do produto, embasado em uma construção teórica, visando apresentar uma solução para o problema definido. Posteriormente, o produto deverá ser testado, ou seja, aplicado no contexto definido.

Após a implementação, os pesquisadores observam quais são as modificações necessárias, a fim de aprimorar o produto por meio de análises, avaliações e validações; as alterações são realizadas e novamente ocorre a utilização do produto com o público-alvo (MATTA; SILVA; BOAVENTURA, 2014). Esse ciclo pode ser repetido várias vezes com a finalidade de refinar cada vez mais o produto, conforme observamos na Figura 1:

Figura 1: Ciclo de aplicação, análise, avaliação e validação da DBR ${ }^{5}$.

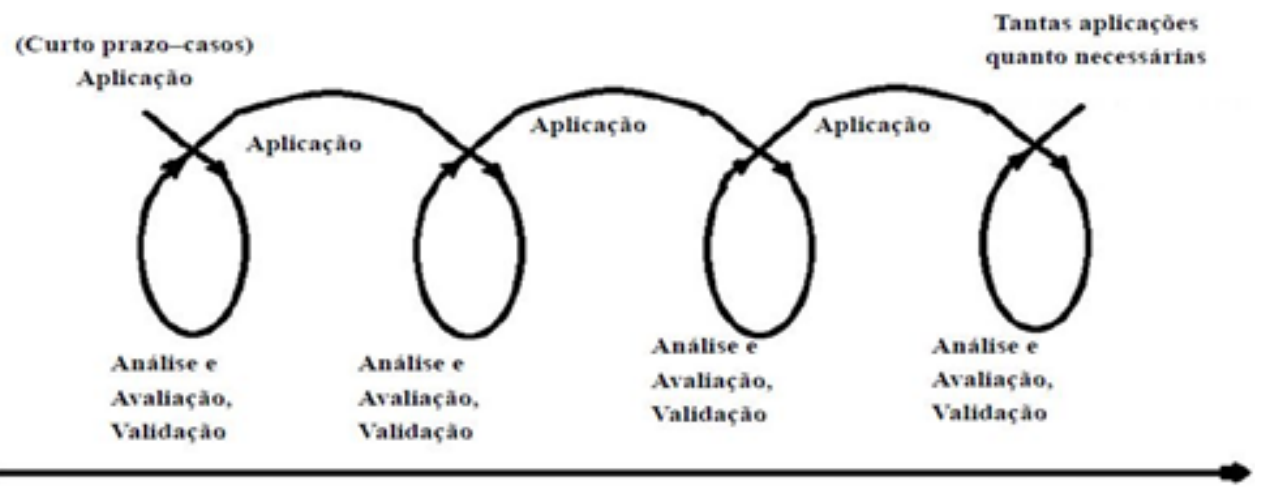

Fonte: Matta, Silva e Boaventura (2014).

A implementação da intervenção com os participantes, a coleta de informações e sua análise na Fase 3, como descrevemos anteriormente, pode se repetir quantas vezes forem necessárias, considerando o tempo disponível para pesquisa, com a finalidade de refinar o produto educacional. Esse é o principal motivo que nos levou a escolher essa metodologia, entre outras vantagens que ela proporciona. Eerde (2013), pesquisadora do Instituto Freudenthal na Holanda, pontua as vantagens de utilizar essa abordagem metodológica nas pesquisas em Educação Matemática. 
- Modela problemas que promovem o pensamento e o aprendizado do aluno;

- Elabora hipóteses sobre o ganho de conhecimento do estudante;

- Conjectura sobre seus próprios papéis como professores a promover e guiar o aprendizado dos alunos;

- $\quad$ Faz questões abertas e de acompanhamento;

- $\quad$ Observa de perto o que os estudantes fazem e dizem;

- $\quad$ Analisa e interpreta o que os estudantes fazem e dizem;

- Remodela problemas e suposições sobre o aprendizado dos alunos baseada nos dados (EERDE, 2013, p. 9, tradução nossa).

Exposto os aspectos da abordagem metodológica do trabalho em andamento, prosseguimos para o detalhamento dos passos do estudo. No Quadro 1 apresentamos um resumo do caminho metodológico seguido à luz da Pesquisa Desenvolvimento.

Quadro 1 - Caminho Metodológico da Pesquisa em Andamento de Acordo com as Fases da Pesquisa DBR

\begin{tabular}{|c|c|c|}
\hline Fase da pesquisa & Tópicos & $\begin{array}{l}\text { Passos metodológicos da pesquisa } \\
\text { em andamento }\end{array}$ \\
\hline \multirow{4}{*}{$\begin{array}{c}\text { Fase 1: Análise do } \\
\text { problema por } \\
\text { investigadores, } \\
\text { usuários e/ou } \\
\text { demais sujeitos } \\
\text { envolvidos em } \\
\text { colaboração. }\end{array}$} & Definição do problema. & $\begin{array}{l}\text { Discussão entre os autores sobre a } \\
\text { práxis docente do orientando. }\end{array}$ \\
\hline & $\begin{array}{l}\text { Consulta recíproca entre } \\
\text { sujeitos engajados na } \\
\text { práxis e investigadores. }\end{array}$ & $\begin{array}{l}\text { Apresentação e aprovação da } \\
\text { problematização com os pares no } \\
\text { contexto escolar. }\end{array}$ \\
\hline & Questões de pesquisa. & $\begin{array}{l}\text { Que aspectos influenciam um } \\
\text { professor ao delinear, aplicar e } \\
\text { revisar uma trajetória de ensino e } \\
\text { de aprendizagem para o 6o ano do } \\
\text { Ensino Fundamental à luz da } \\
\text { Educação Matemática Realística, e } \\
\text { como os contextos nela envolvidos } \\
\text { favorecem um entrelaçamento dos } \\
\text { conteúdos? }\end{array}$ \\
\hline & $\begin{array}{l}\text { Contextualização e/ou } \\
\text { revisão de literatura. }\end{array}$ & $\begin{array}{c}\text { Definição da abordagem da RME } \\
\text { para o produto educacional e } \\
\text { revisão da literatura } \\
\text { correspondente. }\end{array}$ \\
\hline \multirow{3}{*}{$\begin{array}{l}\text { Fase 2: } \\
\text { Desenvolvimento da } \\
\text { proposta de solução } \\
\text { responsiva aos } \\
\text { princípios de design, } \\
\text { às técnicas de } \\
\text { inovação e à } \\
\text { colaboração de } \\
\text { todos os envolvidos. }\end{array}$} & Construção Teórica. & $\begin{array}{l}\text { Estudo de textos científicos sobre a } \\
\text { abordagem RME. }\end{array}$ \\
\hline & $\begin{array}{l}\text { Desenvolvimento de } \\
\text { projeto de princípio para } \\
\text { orientação do plano de } \\
\text { intervenção. }\end{array}$ & $\begin{array}{l}\text { Desenvolvimento da trajetória de } \\
\text { ensino e aprendizagem durante o } \\
\text { curso de especialização. }\end{array}$ \\
\hline & $\begin{array}{l}\text { Descrição da proposta de } \\
\text { intervenção. }\end{array}$ & $\begin{array}{c}\text { Conclusão da proposta didática, sem } \\
\text { processo de implementação com } \\
\text { alunos. }\end{array}$ \\
\hline
\end{tabular}




\begin{tabular}{|c|c|c|}
\hline Fase da pesquisa & Tópicos & $\begin{array}{l}\text { Passos metodológicos da pesquisa } \\
\text { em andamento }\end{array}$ \\
\hline \multirow{12}{*}{$\begin{array}{l}\text { Fase 3: Ciclos } \\
\text { iterativos de } \\
\text { aplicação e } \\
\text { refinamento em } \\
\text { práxis da solução. }\end{array}$} & $\begin{array}{l}\text { Implementação da } \\
\text { intervenção (primeira } \\
\text { iteração) }\end{array}$ & $\begin{array}{l}\text { Escola que o primeiro autor trabalha } \\
\text { como professor. }\end{array}$ \\
\hline & Participantes. & $\begin{array}{l}\text { Oito alunos de 6o ano do Ensino } \\
\text { Fundamental em turmas que o } \\
\text { pesquisador não atua como } \\
\text { professor. }\end{array}$ \\
\hline & Coleta de informações. & $\begin{array}{l}\text { Produção escrita do aluno, diário do } \\
\text { professor e gravação de áudio dos } \\
\text { diálogos entre os sujeitos. }\end{array}$ \\
\hline & Análise das informações. & Análise da produção escrita. \\
\hline & $\begin{array}{l}\text { Implementação da } \\
\text { intervenção } \\
\text { (segunda iteração) }\end{array}$ & $\begin{array}{l}\text { Nova iteração após reformulação do } \\
\text { produto educacional na mesma } \\
\text { instituição. }\end{array}$ \\
\hline & Participantes. & $\begin{array}{l}\text { Uma turma de } 60 \text { ano do Ensino } \\
\text { Fundamental de } 30 \text { alunos na qual o } \\
\text { pesquisador atua como professor. }\end{array}$ \\
\hline & Coleta de informações. & $\begin{array}{c}\text { Produção escrita do aluno, diário do } \\
\text { professor e gravação de áudio dos } \\
\text { diálogos entre os sujeitos. }\end{array}$ \\
\hline & Análise das informações. & Análise da produção escrita. \\
\hline & $\begin{array}{l}\text { Implementação da } \\
\text { intervenção } \\
\text { (terceira iteração) }\end{array}$ & $\begin{array}{l}\text { Última iteração após reformulação } \\
\text { do produto educacional na mesma } \\
\text { instituição. }\end{array}$ \\
\hline & Participantes. & $\begin{array}{l}\text { Uma turma de } 60 \text { ano do Ensino } \\
\text { Fundamental de } 30 \text { alunos na qual o } \\
\text { pesquisador atua como professor. }\end{array}$ \\
\hline & Coleta de informações. & $\begin{array}{c}\text { Produção escrita do aluno, diário do } \\
\text { professor e gravação de áudio dos } \\
\text { diálogos entre os sujeitos. }\end{array}$ \\
\hline & Análise das informações. & Análise da produção escrita. \\
\hline $\begin{array}{l}\text { Fase 4: Reflexão } \\
\text { para produzir } \\
\text { “Princípios de } \\
\text { Design" e melhorar } \\
\text { implementação da } \\
\text { situação. }\end{array}$ & $\begin{array}{l}\text { Princípios de design. } \\
\text { Artefato(s) } \\
\text { implementado(s). } \\
\text { Desenvolvimento } \\
\text { profissional. }\end{array}$ & $\begin{array}{l}\text { Professores e investigadores } \\
\text { obterão uma nova concepção do } \\
\text { produto educacional após o } \\
\text { processo de refinamento. }\end{array}$ \\
\hline
\end{tabular}

Fonte: adaptado de Matta, Silva e Boaventura (2014).

A proposta de problematização emergiu da práxis docente do primeiro autor que atua há cinco anos em turmas do 6ㅇ ano de Ensino Fundamental, em discussões com sua orientadora (segunda autora), na qual reconheceram uma possibilidade de integração curricular entre os conteúdos de conversões de medidas no sistema métrico, área e perímetro, noção intuitiva de escala e operações com números decimais. Integração que vem ao encontro do princípio do entrelaçamento da RME. Esse reconhecimento foi discutido e compartilhado em seu contexto escolar, houve uma aprovação da problematização com os professores e com a equipe pedagógica da instituição de ensino em que o primeiro autor trabalha. 
Assim, estabelecemos a seguinte questão de pesquisa: Que aspectos influenciam um professor ao delinear, aplicar e revisar uma trajetória de ensino e de aprendizagem para o 6o ano do Ensino Fundamental à luz da Educação Matemática Realística, e como os contextos nela envolvidos favorecem um entrelaçamento dos conteúdos?

Para responder essa questão, o objetivo geral da pesquisa em andamento é desenvolver um produto educacional que serve ao processo de ensino e de aprendizagem, analisando o processo de evolução e delineamento dos enunciados das tarefas que o compõem.

A leitura de artigos, livros, dissertações e teses que versam sobre a abordagem de ensino Educação Matemática Realística (VAN DEN HEUVEL-PANHUIZEN, 2010; DE LANGE, 1987; GRAVEMEIJER, 2005; FERREIRA, 2013; SILVA, 2015; SANTOS, 2014) serviram de suporte teórico para elaboração do primeiro desenho da trajetória de ensino e de aprendizagem - uma proposta didática - que foi desenvolvida pelo primeiro autor, em um trabalho de conclusão de um curso de especialização ${ }^{6}$, orientado pela segunda autora. Nessa proposta, ainda sem processo de implementação com alunos, foi realizada uma descrição de intervenções possíveis (Fase 2 do caminho metodológico - Quadro 1).

O contexto selecionado originou-se do hobby da infância e adolescência do primeiro autor, que passava suas tardes esboçando plantas baixas. Essa prática contribuiu para o desenvolvimento de várias habilidades, como a conversão de medidas do sistema métrico para o uso adequado da escala e a multiplicação e adição de números decimais para o cálculo de área e perímetro dos cômodos e de suas representações no projeto. Assim, pode também servir de ponto de partida para que os alunos aprendam a lidar matematicamente com a representação de sua casa ou da sala de aula.

O Quadro 2 apresenta uma descrição sintetizada de cada uma das 14 tarefas presentes no primeiro desenho da trajetória de ensino e de aprendizagem (produto educacional em construção).

Quadro 2 - Design 1 da trajetória de ensino e aprendizagem

\begin{tabular}{|c|c|c|}
\hline Tarefa & Nome & Descrição sintetizada da tarefa \\
\hline 1 & Desenhe sua casa & $\begin{array}{c}\text { Desenhar a forma como é dada a divisão dos } \\
\text { cômodos da casa, como se estivesse vendo } \\
\text { de cima, sem o telhado, sem tomar as } \\
\text { medidas. }\end{array}$ \\
\hline 2 & Procando ideias & $\begin{array}{c}\text { Interação entre dois alunos para descrever as } \\
\text { diferenças de plantas baixas de duas casas. }\end{array}$ \\
\hline 3 & Planta baixa da sala de aula & $\begin{array}{c}\text { Em grupo, tomar as medidas da sala de aula } \\
\text { das paredes, janelas e porta da sala de aula e } \\
\text { esboçar a planta baixa da mesma. }\end{array}$ \\
\hline 5 & Momento de reflexão & Reflexão sobre cada passo da tarefa anterior. \\
\hline 6 & Pesquisa & $\begin{array}{c}\text { Pesquisa do conceito de escala. E interação } \\
\text { com um colega sobre a pesquisa }\end{array}$ \\
\hline 7 & Faça em casa & Esboço da planta baixa do quarto do aluno. \\
\hline
\end{tabular}




\begin{tabular}{|c|c|c|}
\hline Tarefa & Nome & Descrição sintetizada da tarefa \\
\hline 8 & $\begin{array}{l}\text { Observação da tarefa do } \\
\text { colega }\end{array}$ & $\begin{array}{l}\text { Interação entre dois alunos para verificar se } \\
\text { foi respeitado o conceito de escala na planta } \\
\text { baixa. }\end{array}$ \\
\hline 9 & $\begin{array}{l}\text { Área e Perímetro do seu } \\
\text { quarto }\end{array}$ & $\begin{array}{c}\text { Cálculo da área e do perímetro do quarto do } \\
\text { aluno, mesmo que as medidas forem com } \\
\text { números decimais. }\end{array}$ \\
\hline 10 & A cozinha & $\begin{array}{c}\text { Esboço da planta baixa com o uso adequado } \\
\text { da escala e cálculo de área e perímetro. }\end{array}$ \\
\hline 11 & A casa do colega & $\begin{array}{l}\text { Cálculo da área e do perímetro da cozinha ou } \\
\text { do quarto da casa que o professor solicitar. }\end{array}$ \\
\hline 12 & A planta baixa da sua casa & Refazer a tarefa 1. \\
\hline 13 & $\begin{array}{c}\text { Comparação entre as plantas } \\
\text { baixas }\end{array}$ & $\begin{array}{c}\text { Elaborar uma redação, comparando as } \\
\text { plantas baixas esboçadas nas tarefas } 1 \text { e } 12 .\end{array}$ \\
\hline 14 & A casa dos sonhos & Criar a planta baixa da casa dos seus sonhos. \\
\hline
\end{tabular}

Fonte: autoria própria (2017).

O primeiro ciclo iterativo de aplicação (Fase 3 do Quadro 1) foi realizado no segundo semestre de 2017 com um grupo de 8 alunos do 6 ano do Ensino Fundamental de uma escola estadual do Paraná na cidade de Londrina. A formação do grupo de alunos se deu por um convite pelos professores das turmas de 60 ano (turmas em que o pesquisador não é professor regente) para participarem de uma atividade em período contraturno de seus estudos regulares, sendo que 8 alunos aceitaram o convite. O desenvolvimento da trajetória de ensino e de aprendizagem foi em quatro encontros de uma hora e trinta minutos cada.

Os dados coletados para análise a partir da aplicação do lidar dos alunos com cada uma das 14 tarefas são o registro no diário do professor, na produção escrita dos alunos e nos arquivos de áudios gravados. Os alunos, pais e direção da escola assinaram um termo de consentimento livre e esclarecido para utilização e divulgação dos dados.

Para o primeiro semestre de 2018 estão previstos outros dois ciclos de aplicações, conforme especificado no Quadro 2, seguindo o encaminhamento metodológico representado na Figura 1. Nesse texto, especificamente, vamos analisar a evolução, delineamento da quinta tarefa do Quadro 3, de seu estado antes da aplicação até o seu desenho para o segundo ciclo de aplicação - uma reconfiguração.

\section{UM OLHAR PARA A TAREFA 5 - REFINAMENTO NA PRÁXIS}

As tarefas da trajetória de ensino e de aprendizagem possuem uma ligação umas com as outras. Em particular, a quinta tarefa está relacionada com a tarefa anterior - apresentada no Quadro 3 - que propõe aos alunos que façam o desenho da planta baixa da sala de aula. Para isso, foi necessário disponibilizar instrumentos de medidas como trena e fita métrica a fim de os alunos tomarem as medidas das paredes e esboçarem a planta baixa. 
Quadro 3 - primeira versão da tarefa 4

Planta Baixa da Sala de Aula:

Reúnam-se em grupos de 04 alunos, meçam os comprimentos das paredes e façam o desenho da planta baixa da sala de aula.

Fonte: autoria própria (2017).

A tarefa 5 - enunciada no Quadro 4 - em sua primeira versão foi elaborada em formato de questionário. Por meio dela, esperou-se que os alunos individualmente observassem e expressassem a necessidade de padronização de escala de medidas entre o ambiente representado (sala de aula) e o desenho da planta baixa ${ }^{7}$ construído na tarefa 4 em grupo, com o intuito de oportunizar aos estudantes que conhecimentos matemáticos, como conversão de medidas e ideias intuitivas de proporcionalidade, fossem desenvolvidos.

Quadro 4 - primeira versão da tarefa 5

Momento de Reflexão:

A tarefa a seguir deverá ser realizada individualmente.

a) Como o seu grupo mediu o comprimento de cada uma das paredes?

b) Qual é a medida do comprimento da parede na qual o quadro negro está localizado?

c) Na planta baixa da sala de aula que você acabou de desenhar, qual é a medida do comprimento da linha desenhada que representa a parede do quadro negro?

d) Um centímetro da linha desenhada na planta baixa da parede em que se localiza a lousa representa quantos centímetros da parede real?

e) Um centímetro da linha desenhada na planta baixa da parede em que se localiza a lousa representa quantos metros da parede real?

f) Qual é a medida do comprimento das paredes ao lado da parede na qual se localiza o quadro?

g) Na planta baixa da sala de aula que você acabou de desenhar, qual é a medida do comprimento da linha que representa as paredes do lado da parede na qual o quadro está localizado?

h) Um centímetro da linha desenhada na planta baixa das paredes ao lado da parede em que se localiza o quadro representa quantos centímetros destas paredes reais?

i) Um centímetro da linha desenhada na planta baixa das paredes ao lado da parede em que se localiza o quadro representa quantos metros destas paredes reais?

j) Um centímetro nas paredes correspondentes ao quadro negro e às paredes do lado do quadro, correspondem à mesma medida da parede?

k) Comente o motivo da sua resposta no item "j".

l) Agora que você refletiu, refaça a planta baixa da sua sala de aula.

m) Essa planta baixa tem alguma(s) alteração(ões) em relação à desenhada na tarefa anterior? Qual ou quais?

Fonte: autoria própria (2017).

As possibilidades de resposta do item "a" dessa questão se referem à descrição de como a primeira parte da tarefa anterior foi desenvolvida. As respostas dos itens " $b$ " e " $f$ " dependem das medidas da sala de aula em que os alunos estudam, bem como os itens " $c$ " $e$ " $g$ ", pois as respostas dependem das medidas dessas paredes nas representações das plantas baixas. Nos itens " $d$ " e " $h$ ", por sua vez, o aluno precisará dividir a medida da parede pela medida da representação da parede no esboço da planta baixa. Para isso, é necessário que ambas estejam na mesma medida (centímetros ou metros). As respostas desses itens dependem das medidas dessas paredes empregadas na representação da planta baixa. 
Nos itens " $e$ " e " $\mathrm{i}$ ", o aluno pode realizar a conversão de medidas de centímetro para metro em relação aos itens " $d$ " e " $h$ " ou refazer o cálculo dividindo a medida da parede (em metros) pela medida da mesma parede na planta baixa (em centímetros), pois a resposta depende da medida dessa parede na representação da mesma. Assim, os alunos que ainda não souberem converter metros em centímetros, terão a oportunidade de lidar com relações entre medidas.

A intencionalidade pedagógica do item " $\mathrm{j}$ " é levar o aluno a refletir se a escala adotada nas paredes de medida distintas é a mesma. No item seguinte, é solicitada uma justificativa dessa resposta, com o objetivo de que o aluno perceba a necessidade de os dois pares de paredes paralelas serem representados por meio da mesma escala.

Treffers e Goffree (1985) mencionam que os contextos das tarefas podem desempenhar na formação dos estudantes algumas funções: formação de conceito; modelo de formação; aplicabilidade; exercício de habilidades específicas em situações aplicadas. A partir das intencionalidades mencionadas da tarefa 5, reconhecemos que o contexto planta baixa pode servir para que os estudantes tenham um acesso natural para a formação de conceitos da matemática, sendo possível: ser suporte para a aprendizagem de operações e procedimentos formais (escalas, por exemplo) em conjunto com as outras tarefas; servir como suporte para a compreensão de conceitos matemáticos; reconhecer a realidade como fonte e domínio para desenvolver habilidades.

Ao elaborar a tarefa, os autores buscaram interpretar a situação de ensino com base no conhecimento do contexto planta baixa. Buscou-se resolver antecipadamente de um modo detalhado e colocar-se no lugar do aluno para compreender os possíveis erros e resoluções que poderiam apresentar. Conforme Van den Heuvel-Panhuizen (2000), sem manter uma perspectiva da trajetória de ensino e de aprendizagem com vistas ao que se deseja, não é possível orientar a aprendizagem dos estudantes. Complementamos, mesmo mantendo essa perspectiva, é preciso reavaliá-la e reconstruí-la a cada passo dos processos de ensino e de aprendizagem.

Essa necessidade de reflexão sobre a prática e em especial as tarefas utilizadas em contexto de sala de aula é evidenciada já no primeiro encontro da primeira aplicação da trajetória de ensino e de aprendizagem. Por uma questão de escolhas e de estrutura textual, iremos focar nossa discussão na aplicação da tarefa 5. Essa tarefa foi aplicada no segundo encontro, resolvida pelos oito alunos participantes.

O número de questionamentos da tarefa, apesar de grande, tinha por intenção ser um "guia de reflexão", para que, por meio deles, os estudantes explicassem suas estratégias e resolução da tarefa. Entretanto, ao aplicá-la, houve muitos questionamentos por parte dos estudantes, pois, para eles, as questões não estavam tão claras, eles tiveram dificuldades em identificar qual parede se referia cada item da questão. Além disso, a quantidade de questões os desmotivou, a interpretação das perguntas não ocorreu de modo imediato.

Nesta direção, reconhecemos que para além de elaborar "boas" questões (tarefas) é preciso que elas favoreçam boas intervenções orais e escritas, pois por meio das intervenções será possível flexibilizar e oportunizar que os alunos apresentem seu poder matemático, bem como "abrir a possibilidade de realizar 
uma reinvenção guiada, com o qual o aluno pode iniciar um processo de matematização, seguindo seu próprio percurso de aprendizagem" (MENDES, 2014, p. 204).

No momento da aplicação, para superar tais dificuldades o professor decidiu ler junto com os alunos as questões que apresentaram dúvidas e, quando necessário, apontou para a parede que a pergunta se referia.

Mesmo com as dificuldades mencionadas, todos os alunos participantes, ao refazer a planta baixa da sala de aula no item "I" dessa questão, utilizaram um centímetro da planta baixa para representar as mesmas medidas nas quatro paredes, ou seja, fizeram uso intuitivo do conceito de escala. A Figura 2 e a Figura 3 são exemplos da evolução das plantas construídas por um aluno na tarefa 4 e no item "I" da tarefa 5, respectivamente:

Figura 2 - Produção do Aluno A, antes dos questionamentos da tarefa 5.

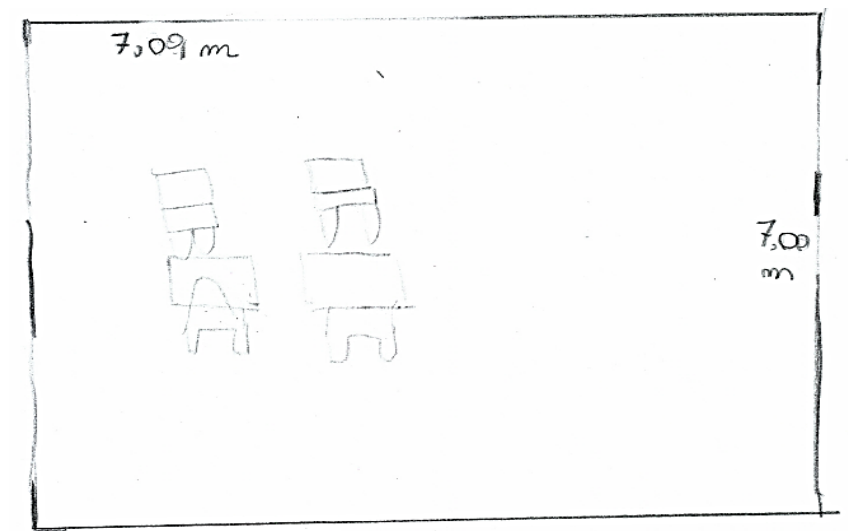

Fonte: arquivo próprio (2017).

Figura 3 - Produção do Aluno A, após os questionamentos da tarefa 5

I) Refaça a planta baixa da sua sala de aula.

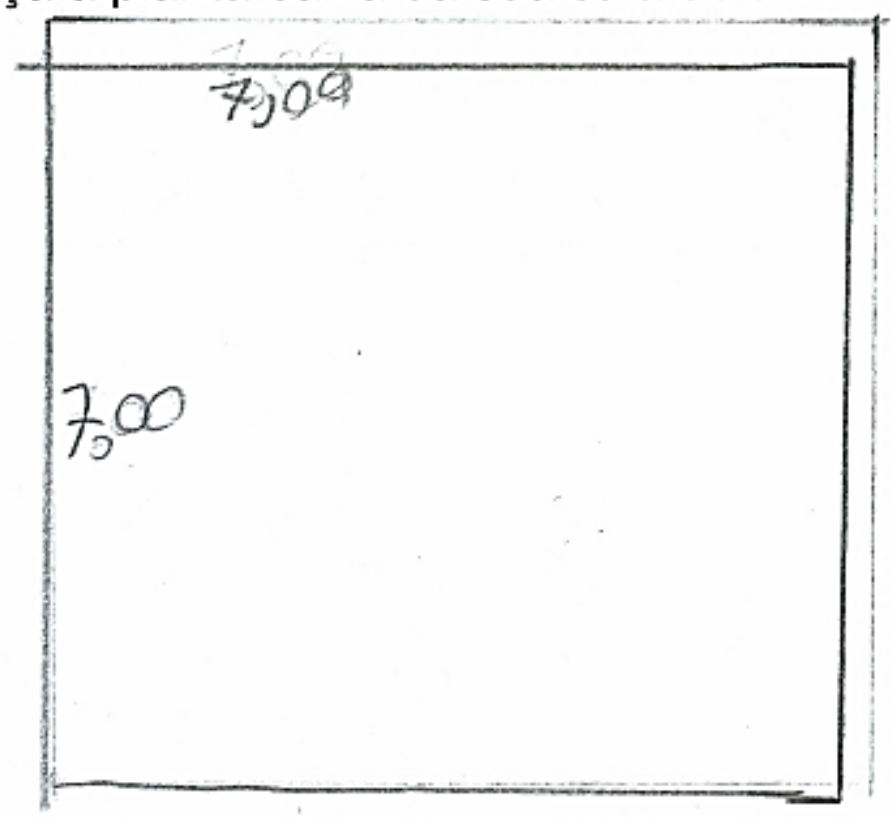

Fonte: arquivo próprio (2017). 
Apesar das medidas das paredes da sala de aula serem próximas nos dois registros, na primeira representação (Figura 2) existe uma diferença entre o comprimento e a largura. Já na segunda (Figura 3), as proporções dos lados com as referidas medidas foram respeitadas.

Ao refazer a planta da sala e após as reflexões promovidas por vários itens desse questionário, cuja intenção foi intervir no processo de construção do conhecimento, os alunos perceberam a necessidade da utilização de um parâmetro de medidas entre o desenho da planta baixa e o ambiente representado, sem a necessidade de nominar esse conceito de escala, uma vez que a sistematização desse conceito se deu nas tarefas sequentes da trajetória.

O princípio dos níveis destacou-se nessa tarefa. Após a compreensão de cada item do questionamento, os alunos perceberam a necessidade de um centímetro na planta baixa representar a mesma medida em cada uma das paredes da sala de aula. Dessa forma, o próprio aluno desenvolveu o conhecimento por meio de uma situação baseada na tarefa desenvolvida, o que possibilita a evolução para um nível de conhecimento mais elaborado. Além disso, todos alunos tiveram a oportunidade de produzir conhecimentos. As reflexões possibilitaram que o aluno desenvolvesse um conceito intuitivo de escala por meio da abordagem da RME.

\footnotetext{
Um aspecto importante desta abordagem é que cria oportunidades para os alunos desenvolverem o conhecimento matemático fundamentado em experiências do dia a dia. Mais importante ainda, deixa em aberto a conexão com essas fontes. Isto, por sua vez, permite aos alunos evoluírem para níveis de compreensão mais concretos, se eles resolverem problemas. Por isso, esta abordagem deixa espaço para os alunos trabalharem a diferentes níveis (GRAVEMEIJER, 2005, p.15).
}

Após vivenciar a primeira aplicação, analisar e avaliar os dados coletados, iniciamos o processo de validação das tarefas da trajetória. Especificamente com relação a tarefa 5, foi possível avaliar que as intencionalidades pedagógicas das perguntas presentes no questionário foram adequadas, entretanto, foi preciso reconfigurar o design da tarefa para que alunos de 60 ano do Ensino Fundamental ao resolverem não tenham dificuldades em interpretar o texto. Os questionamentos podem estar no planejamento do professor, como questionamentos potenciais para orientar os alunos no desenvolvimento da tarefa, favorecendo uma maneira de reinvenção guiada.

Em seu novo design, decidimos utilizar os desenhos das paredes a localização dos alunos: 
Quadro 4 - segunda versão da tarefa 5

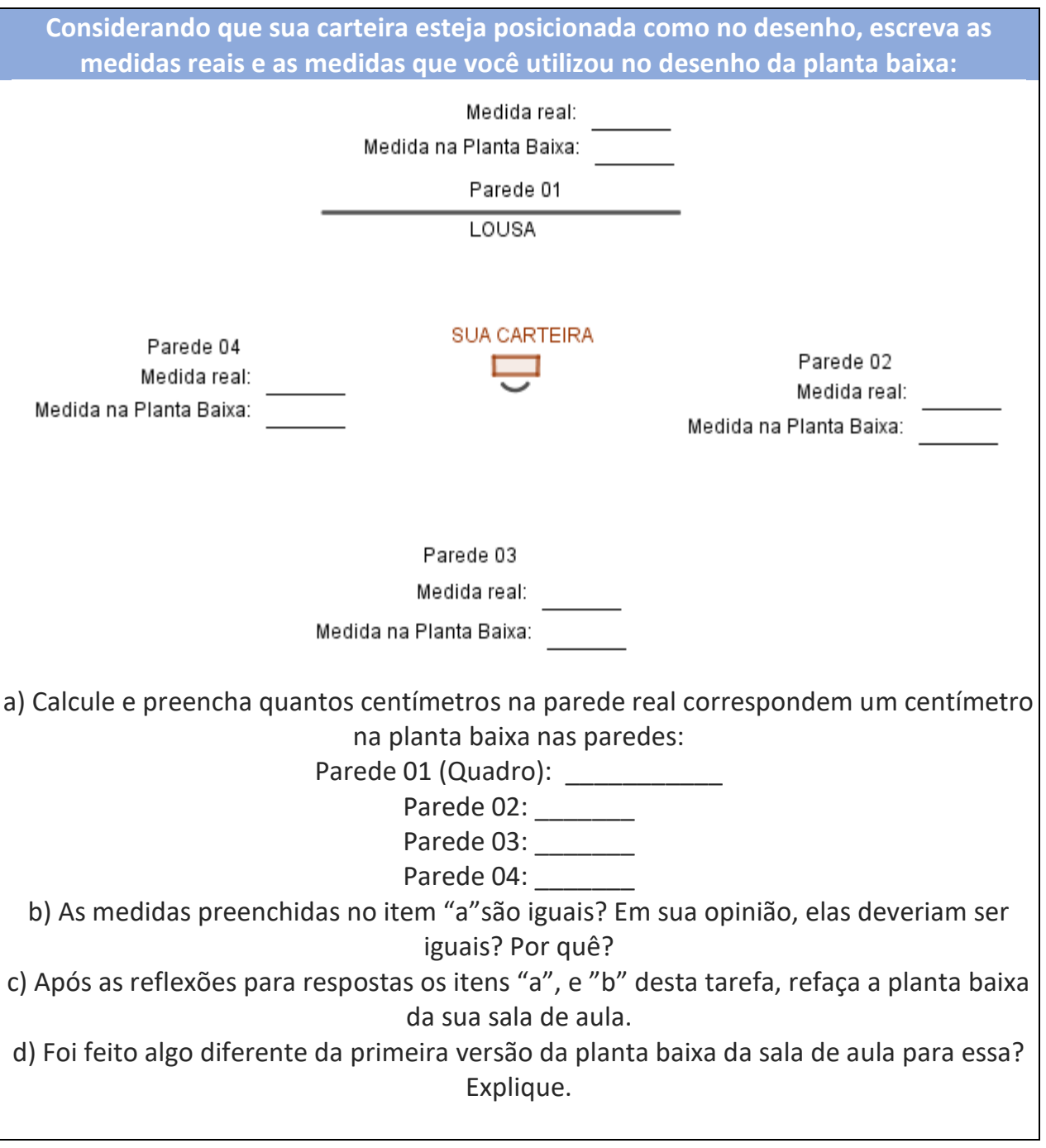

Fonte: autoria própria (2017).

Espera-se que na primeira parte dessa nova versão da tarefa 5, o aluno preencha as medidas utilizadas no desenho da planta baixa da tarefa anterior e as medidas reais das paredes que foram representadas. Essa nova "forma" tem a intenção de proporcionar ao aluno uma visualização dos dados necessários para responder os itens dessa questão, assim como melhorar a comunicação entre professor e aluno, uma vez que na primeira versão da tarefa os alunos tiveram dificuldade de interpretar e lidar com os seus itens.

O item "a" requer que o aluno compare os dados que coletou na primeira parte da tarefa e apresente a medida que 1 centímetro da planta baixa representa em cada uma das quatro paredes da sala de aula. $\mathrm{O}$ aluno precisa perceber que essa resposta somente será obtida corretamente se efetuar a divisão da medida real da parede com a medida dessa mesma parede representada na planta baixa.

A intencionalidade do item seguinte, "b", é proporcionar uma reflexão acerca da necessidade de padronização das medidas que um centímetro deve representar em qualquer planta baixa. Essa reflexão se dá a partir da comparação entre as medidas que um centímetro representou na planta baixa desenhada na tarefa 4 . 
Ao refazer a planta baixa no item " $c$ ", espera-se que o aluno utilize os conhecimentos refletidos nos itens " $a$ " e " $b$ ". Desse modo, caso o aluno não tenha padronizado as medidas que um centímetro representa em cada parede na tarefa 4, a expectativa é que represente-as fazendo uso intuitivo do conceito de escala que será sistematizado posteriormente.

Ao responder o item "d", o aluno deverá comparar as duas versões de desenho e verificar as diferenças. Espera-se que os alunos expressem intuitivamente elementos que provoquem uma discussão acerca do uso de escala, assim como problemas em representações que não obedecem de sua utilização. Esses elementos nortearam discussões do professor com toda a turma.

Cabe salientarmos que essa tarefa, assim como as demais, passaram por um processo de refinamento - fechando o primeiro ciclo de aplicação. Iniciamos um novo ciclo de aplicação e, durante esse procedimento - análises, avaliações e validações - as tarefas pertencentes à trajetória de ensino e aprendizagem poderão passar por alterações e, até mesmo, serem substituídas ou excluídas.

A compreensão da necessidade do uso intuitivo de escala a partir da atividade informal de medir uma planta baixa revela a obtenção do objetivo inicial da tarefa pelos oito participantes, evidenciando o princípio de níveis da RME. Esse é um aspecto determinante para validação e manutenção dessa tarefa para a segunda versão da trajetória de ensino e de aprendizagem, contudo, as diversas dúvidas que os alunos apresentaram neste processo expressam a necessidade de reconfiguração do enunciado da tarefa.

Desse modo, a apreciação do modo de lidar dos alunos com a tarefa, os resultados em suas produções e o reconhecimento do princípio de níveis no desenvolvimento da tarefa foram aspectos relevantes que influenciaram o processo de análise, avaliação, validação e reformulação da tarefa 5.

Todo esse processo de análise, avaliação e validação são momentos em que possibilitam uma reflexão e aprimoramento da prática pedagógica, para além da criação de uma trajetória de ensino e de aprendizagem desejada. Assim como explorar contextos em tarefas de matemática em aulas desenvolvidas à luz dos princípios da Educação Matemática Realística faz-se uma alternativa para superar uma abordagem de ensino de matemática convencional.

\section{ALGUMAS CONSIDERAÇÕES: POSSIBILIDADES ACERCA DA PESQUISA}

Entre os aspectos que influenciaram o redesenho do enunciado da Tarefa 5, destaca-se a análise do modo de lidar de alunos e a percepção do docente acerca das dificuldades de alunos durante a realização da tarefa. Esse redesenho tem a intenção primeira de evitar que ocorram as mesmas dúvidas acerca do enunciado da tarefa. Esse processo evidencia como a prática pedagógica precisa ser um processo de constante reflexão e planejamento.

Um objetivo subjacente desse trabalho residiu em provocar um repensar o ensino de matemática por meio de desenvolver, aplicar, analisar e avaliar a evolução de uma tarefa matemática à luz da Educação Matemática Realística. Nessa direção, a elaboração de produtos educacionais para a utilização no contexto escolar (assim como discussão de tarefas matemáticas), aliada às atitudes 
pedagógicas adequadas à Educação Matemática Realística é um caminho a ser explorado em discussões em momentos de formação com professores de nosso país.

Os princípios da abordagem de ensino Educação Matemática Realística estão fortemente presentes na proposta didática em desenvolvimento. O princípio do entrelaçamento com a integração de conteúdos de domínio matemáticos distintos, o princípio de níveis é identificado na tarefa 5, por exemplo, pois a mesma parte da atividade informal das medidas de um esboço de planta baixa para a compreensão da necessidade da utilização do conceito de escala, com o desenvolvimento da ideia intuitiva de proporcionalidade. O contexto selecionado favorece a identificação do princípio da realidade. A interatividade é reconhecida nas tarefas desenvolvidas em grupo, como a tarefa 4 . O princípio da orientação ocorre pela utilização da estratégia de ensino reinvenção guiada e o princípio da atividade pode ser observado em tarefas não rotineiras propostas ao aluno no desenvolvimento de atividades humanas para emergir os conhecimentos matemáticos.

O processo de delineamento refinará, ainda mais, a proposta didática - a trajetória de ensino e de aprendizagem. Possivelmente ocorrerão exclusões de algumas tarefas, acréscimo de outras, alterações de enunciados, desmembramento de uma tarefa em duas ou mais, aglutinação de duas ou mais tarefas em uma, revisão da forma como será conduzida e dos objetivos com cada uma. "Olhar" para todo esse processo (ou parte dele, como é o caso desse trabalho) pode subsidiar professores a superar uma abordagem convencional de ensino. Não temos intenção de propor a utilização do material em desenvolvimento como o único recurso utilizado para o trabalho pedagógico dos conhecimentos matemáticos explorados, mas como uma alternativa curricular que integra os conteúdos matemáticos a partir de uma situação real, assim como inspirar o nascimento de outras trajetórias de ensino e de aprendizagem. Reconhecendo na elaboração delas uma oportunidade de momentos de formação.

A versão final da trajetória de ensino e aprendizagem será acompanhada de um guia, a fim de orientar professores que venham a fazer uso do produto educacional em desenvolvimento. Esse material contemplará direcionamentos de como conduzir o processo de ensino e aprendizagem com a abordagem Educação Matemática Realística em cada uma das tarefas. 


\title{
The delimitation of mathematical tasks in the light of the design research: an opportunity of reflection of the pedagogical practice
}

\begin{abstract}
The present work is a review of an ongoing master's degree research, which aims to analyze the process of elaborating a teaching and learning trajectory - involved in the context of low plants - for students of the 6th year of Elementary School. All reflection is based on the principles of the teaching approach Realistic Mathematical Education that: recognizes mathematics as a human activity, proposes a classroom context in which the student recognizes himself as the protagonist and responsible for his / her learning process and, the teacher as a guide that guides and accompanies its students, through interventions, toward the goals of the desired education. Specifically, in this work, the objective is to present a reflection constructed from an iterative cycle of application and refinement of one of the tasks that make up the first design of the teaching and learning trajectory, in order to present and discuss aspects of its application, analysis, evaluation and reformulation for new design and new iterative cycle. It is a qualitative study of an interpretive nature in which the process of its elaboration is based on the Research of Development (Design Research). The phase of application of the first iterative cycle occurred with a group of eight students from the 6th year of elementary school in a state school in Paraná, in the second half of 2017. We could infer that for a teacher to experience and analyze the process of evolution and delineation of enunciates of mathematical tasks makes possible a reflection and improvement of its pedagogical practice, as well as exploring contexts in mathematical tasks in classes developed in the light of the principles of Realistic Mathematical Education, it becomes an alternative to surpass a approach of teaching of conventional mathematics.
\end{abstract}

KEYWORDS: Realistic Mathematics Education. Trajectory of teaching and learning. Mathematical tasks. Design Research. 


\section{AGRADECIMENTOS}

${ }^{1}$ Do inglês Realistic Mathematics Education.

${ }^{2}$ Esse produto educacional está em desenvolvimento pelo primeiro autor, sob a orientação da segunda, durante seus estudos de pós-graduação em um Programa de Mestrado Profissional em Ensino de Matemática.

${ }^{3}$ Conforme Van den Heuvel-Panhuizen (2002), uma trajetória de ensino e de aprendizagem tem três propósitos entrelaçados: uma trajetória de aprendizagem, uma visão geral dos processos de aprendizagem dos estudantes; uma trajetória de ensino com indicações didáticas que descrevem um ensino que articula e estimula a aprendizagem e um esboço do assunto do currículo de matemática a ser ensinado.

${ }^{4}$ Consideraremos convencionais os papéis em que o professor é o detentor do conhecimento e esse deve repassá-lo para seus alunos, geralmente por meio de aulas expositivas, e os alunos, como receptores, devem reproduzir os conteúdos estudados.

${ }^{5}$ Os autores do referido artigo consideraram o nome em inglês Design-Based Research (DBR).

${ }^{6}$ Especialização em Educação Matemática e Ensino de Ciências da Universidade Tecnológica Federal do Paraná, Campus Londrina.

${ }^{7}$ Apesar de os alunos estarem em grupo, cada aluno fez o seu registro em seu material.

\section{REFERÊNCIAS}

ALENCAR BARBOSA, J. C.; OLIVEIRA, A. M. P. Por que a pesquisa de desenvolvimento na Educação Matemática? Perspectivas da Educação Matemática, v. 8, n. 18, 2015.

DE LANGE, J. Mathematics, Insight and Meaning. Utrecht: OW \& OC, 1987.

VAN EERDE, H. A. A. Design research: Looking into the heart of mathematics education. In: Proceeding The First South East Asia Design/Development Research (SEA - DR) International Conference, 2013, Sriwijaya University. Anais... Palembang: UNSRI, 2013, p. 1-10.

FARIA, E. T.O professor e as novas tecnologias. Ser professor, v. 5, p. 57-72, 2004.

FERREIRA, P. E. A. Enunciados de Tarefas de Matemática: um estudo sob a perspectiva da Educação Matemática Realística. 2013. 121f. Tese (Programa de Pós Graduação em Ensino de Ciências e Educação Matemática) - Universidade Estadual de Londrina, Londrina, 2013. 
FERREIRA, P. E. A.; DE BURIASCO, R. L. C. Educação matemática realística: uma abordagem para os processos de ensino e de aprendizagem - Educação Matemática Pesquisa, v. 18, n. 1, 2016.

GRAVEMEIJER, K.P.E. O que torna a Matemática tão difícil e o que podemos fazer para alterar. Educação matemática: caminhos e encruzilhadas. Lisboa: APM, p. 83-101, 2005.

MATTA, A. E. R.; DA SILVA, F. P. S.; BOAVENTURA, E. M. Design-based research ou pesquisa de desenvolvimento: metodologia para pesquisa metodologia para pesquisa de desenvolvimento: metodologia para pesquisa aplicada de inovação em educação do século xxi. Revista da FAEEBA - Educação e Contemporaneidade, v. 23, n. 42, 2014.

MENDES, M. T. Utilização da Prova em Fases como recurso para regulação da aprendizagem em aulas de cálculo. 2014. 275f. Trabalho Tese de doutorado (Programa de Pós-Graduação em Ensino de Ciências e Educação Matemática) Universidade Estadual de Londrina, 2014.

SARAIVA, M.; PONTE, J. P. O trabalho colaborativo e o desenvolvimento profissional do professor de Matemática. Quadrante, p. 25-52, 2003.

SANTOS, E. R. Análise da produção escrita em matemática: de estratégia de avaliação a estratégia de ensino. 2014. Tese (Doutorado em Ensino de Ciências e Educação Matemática) - Universidade Estadual de Londrina, Londrina. 2014.

SILVA, G. S. Uma configuração da reinvenção guiada. 2015. 94f. Dissertação (Mestrado em Ensino de Ciências e Educação Matemática) - Universidade Estadual de Londrina, Londrina, 2015.

TREFFERS, A.; GOFFREE, F. Rational analysis of realistic mathematics education. In: ISSN 1980-4415 DOI: http://dx.doi.org/10.1590/1980-4415v29n52a02 Bolema, Rio Claro (SP), v. 29, n. 52, p. 452-472, ago. 2015472 STREEFLAND, L. (Ed.). Proceedings of the 9th International Conference for the Psychology of Mathematics Education. Utrecht, The Netherlands: OW\&OC. 1985. p. 97-123.

VAN DEN HEUVEL-PANHUIZEN, M. V. D. Mathematics education in the Netherlands: A guided tour. Freudenthal Institute Cd-rom for ICME9. Utrecht: Utrecht University, 2000. CD-ROM. 
In: The Annual Conference of the Mathematics Education Research Group of Australasia, 2010, Australia, p. 3-7.

WEININGER, M. J. Do aquário em direção ao mar aberto: Mudanças no papel do professor e do aluno. In: LEFFA, Vilson J.. (Org.). O Professor de Línguas Estrangeiras: construindo a profissão. Pelotas: Editora da Universidade Católica de Pelotas, 2001, p. 41-68.

Recebido: 27 fev. 2018

Aprovado: 04 jun. 2018

DOI: 10.3895 /actio.v3n3.7945

Como citar:

MARINO, C. A.; MENDES, M. T. O delineamento de tarefas matemáticas à luz da pesquisa de

desenvolvimento: uma oportunidade de reflexão para a prática pedagógica. ACTIO, Curitiba, v. 3, n. 3, p

431-450, set./dez. 2018. Disponível em: <https://periodicos.utfpr.edu.br/actio>. Acesso em: XXX

Correspondência:

Cleiton Antonio Marino

Estr. dos Pioneiros, n. 3131 - Jardim Morumbi, Londrina, Paraná, Brasil.

Direito autoral: Este artigo está licenciado sob os termos da Licença Creative Commons-Atribuição 4.0

Internacional.

(c) (i) 